Available online at GSC Online Press Directory

GSC Biological and Pharmaceutical Sciences

e-ISSN: 2581-3250, CODEN (USA): GBPSC2

Journal homepage: https://www.gsconlinepress.com/journals/gscbps

(RESEARCH ARTICLE)

\title{
Modeling sexual differences of body size variation in ground beetles in geographical gradient (The case study in Pterostichus oblongpunctatus Fabricius, 1787)
}

\author{
Raisa A Sukhodolskaya ${ }^{1, *}$, Anatoly A Saveliev², Nadezhda L Ukhova ${ }^{3}$, Iraida G Vorobyova ${ }^{4}$, Igor A \\ Solodovnikov ${ }^{5}$, Anatoliy L Anciferov ${ }^{6}$, Tatyana A Gordienko ${ }^{1}$, Rifgat R Shagidullin ${ }^{1}$ and Dmitriy N Vavilov ${ }^{1}$ \\ ${ }^{1}$ The Institute of Problems in Ecology and Mineral Wealth, Tatarstan Academy of Sciences, Kazan, Russia. \\ ${ }^{2}$ Kazan (Volga Region) Federal University, Kazan, Russia. \\ ${ }^{3}$ Visimskiy Nature Reserve, Kirovgrad, Russia. \\ ${ }^{4}$ Mariy State University, Yoshkar Ola. Russia. \\ ${ }^{5}$ Educational establishment, Vitebsk State P.M. Masherov University, Vitebsk, Belarus. \\ ${ }^{6}$ Kostroma Museum-Reserve, Kostroma, Russia.
}

Publication history: Received on 27 November 2020; revised on 14 December 2020; accepted on 16 December 2020

Article DOI: https://doi.org/10.30574/gscbps.2020.13.3.0388

\begin{abstract}
Fleshing out the mechanisms of Bergmann rule, we found saw-tooth pattern in body size variation in ground beetle Pterostichus oblongopunctatus. We sampled beetles in 2010 - 2018 at the forest undisturbed plots on the broad territory in Russia and Belarus. Investigating regions covered territory, extending to 3 degrees latitude and 31 degrees longitude. We measured six traits in every of 3294 caught individuals. ANOVA showed that geographical location and sex affected significantly body size of the species studied. Mean values of each trait changed significantly from one studied region to another in females and males as well. Sexual size dimorphism in species was female-biased. We performed models in $\mathrm{R}$ to estimate the steepness of body size variation in both sexes. In overwhelming majority of cases that parameter was equal in both sexes. So the hypothesis, that male's variation is steeper in latitude gradient was not confirmed.
\end{abstract}

Keywords: Body size variation; Sexual size dimorphism; Ground beetles; Geographical gradient; Modeling; Saw-tooth pattern; Bergmann rule

\section{Introduction}

Large-scale patterns of body size variation have occupied biologists for over a century. One prominent pattern is Bergmann's rule, which originally referred to clinal geographic variation among endothermic (warm-blooded) species only. The latter tend to be bigger in colder climates [1-4]. That phenomena was explained as follows: larger individuals possess smaller surface-to-volume ratios and it is more conducive to conserving heat in cold climates. Then this rule was extended to ectothermic (cold-blooded) organisms [5]. For them the cause must be different, as especially small ectotherms acclimate to ambient temperature almost instantly [6].

Among large-scale patterns of body size variation counter gradient variation [7] and saw-tooth variation exist. The latter considers, that variation in number of generations per season (i.e. voltinism) affects time constraints. The traditional view about how latitudinal or altitudinal gradient in season length affects the evolution of development time and body size in potentially multivoltine insects was developed by S. Masaki [8,9] and formalized by D. Roff [10,11] and Y. Iwasa et al. [12].They assumed that development time and body size are positively correlated among genotypes, and insects use all available time for growth to maximize adult body size and thus fecundity. Consequently, both development time

*Corresponding author: Raisa A. Sukhodolskaya; Phone +79503152619; E-mail: sukhodolskayaraisa@gmail.com The Institute of Problems in Ecology and Mineral Wealth, Tatarstan Academy of Sciences, Kazan, Russia. 
and body size are expected to increase along a gradient of increasing season length (i.e. with decreasing latitude or altitude) as long as voltinism does not change. Decreases in both traits are expected at the season lengths that facilitate the emergence of a new generation within the season, because time available per generation decreases at these transitions. Thus, the traditional saw-tooth cline arises across phenologies because of genetic adaptation to local conditions. The examples of saw-tooth variation were presented in recent years [13,14]. In addition the third pattern of body size variation in latitude gradient can occur. It is counter-gradient variation, known as the hypothesis of latitude compensation [15]. The mechanism can be described as follows: in high latitudes specimen compensate short breeding period by higher (it is genetically coded) rate of growth, compared with conspecificians in low latitudes. In simplest case the rate of growth is the body size per the unit of development time, the utterly exact compensation of breeding season constraints at the certain latitude (the environmental component) will occur in that situation, when growth rate (genetic component) evolves in the way to keep phenotypic body size equal at all latitudes. If increasing growth rate perfectly compensates for the decrease in generation time, body size remains constant over the whole gradient of season length.

No less important aspect in studying Bergmann's clines is the difference of their occurrence in males and females. Prominent body size pattern is Rensch's rule, the observation widespread in the animal kingdom that male body size varies (or evolutionarily diverges) more than female body size among related species, such that male-biased sexual size dimorphism increases and female-biased sexual size dimorphism decreases with body size [16-18]. Rensch's rule is manifested statistically in allometric slopes greater than one when male size is regressed on female size [19]. The problem regarding the scaling of SSD with body size exists. In the first place, there is the question of the taxonomic level at which it is studied - inter-specific or intra-specific. Most studies of the scaling of SSD with body size either phylogenetically based or not have been performed across species at different levels [20]. An additional problem is that of the appropriate measurements for analyzing SSD [20]. Taking into account that different traits variation can be different in the same species, preferably several traits must be under investigation [21].

The few studies to date testing whether intraspecific variation in sexual size dimorphism conforms to Rensch's rule have yielded mixed results [22-26]. Blanckenhorn et al. [27] in the large review studied latitude clines in males and females taking into account published data and their own investigations. Males latitudinal clines were steeper than those of females in a significant majority of species (66 of 98), confirming the male - steeper hypothesis connecting Bergmann's and Rensch's rules, regardless of whether the species displays male- or female-biased size dimorphism. That supported the existence of a geographic version of Rensch's rule. Of course, that left approximately one-third of the species showing the opposite trend, underscoring the fact that several factors must be involved in generating those patterns. As previously shown for arthropods [28] they found a continuum of Bergmann (58 species) and converse Bergmann clines (40 species) in this taxonomically more diverse data set [29]. Interestingly, regardless of which sex was larger, the latitudinal decrease in male size (relative to female size), and hence change in sexual size dimorphism, in species with converse Bergmann clines was generally more pronounced than the corresponding relative male size increase with latitude in species with Bergmann clines, implying that dimorphism changed faster with latitude in the former group. The authors concluded that relationship between cline type and magnitude of divergence in male and female size required further study.

Thus and so, we tried to replenish the cited above study with new research improving data analysis design. We investigated latitudinal body size variation in carabid beetle Pterostichus oblongopunctatus Fabricius, 1787. Ground beetles are famous for their indicative properties because of their high sensitivity to environmental effects [30]. This is a large species-rich family in Coleoptera.

Despite plenty of papers on carabids, very few discuss their body size variation along geographical gradients. Among them K. Homburg investigation, revealing hump-shaped body size variation in North Africa - North Europe region [31], but that work was done on interspecific level. Intra-specific studies in carabids body size variation in latitude/altitude gradient are scarce. They are often limited by the single trait investigating or are done on the community level [32-35]. Ground beetles vary greatly in size and shape [36] but not in the magnitude of SSD [37]. Some species are fairly common. They are easy to collect in a large range of biotopes and they have large geographic distributions. These allows the sampling of several populations inhabiting different or even contrasting environments. The latter is relevant because it has been proposed that in species showing intraspecific geographic variation in body size the link between body size variation pattern and scaling SSD with body size might exist [27]. In this sense carabids are an excellent model for the comparative analysis of SSD and although a few studies have been performed [38-39], virtually little is known about patterns of SSD at the intraspecific level concerning the points mentioned in this Introduction.

The aim of our study was to estimate body size variation in P. oblongopunctatus in geographical gradients (in this case latitude), taking into study six morphometric traits. Variation of different traits in the same species can have different 
directions [40]. In regard to geographical gradients, as M. Shelomi has noted, "..if you measured a leg instead of a wing, or males instead of females or looked at multiple species together instead of just one, your results would be different" [41]. The work had to be done separately in males and females in order to verify the hypothesis about the greater steepness of traits variation in males in latitude gradient.

\section{Material and methods}

Pterostichus oblongopunctatus Fabricius, 1787 is a small-medium size widespread beetle omnipresent throughout majority of European ecosystems [42] with higher occurrence in litter-rich soils of humid deciduous broadleaved forests $[43,44]$. Despite of that, the species is noted in habitats of significant temperature span and found susceptible to multitude of environmental factors [45]. Research of sensitivity of animal's metric traits to both human activity [46] and natural conditions are noted [47]. The animal is mobile and notable quantity of specimen is found in ordinary pitfall traps, hereby providing raw material for statistical analysis. Despite of textbook attribution to ecosystems of Europe [48], given species is found abundant further in Palearctic. Conducted research provides insight on their presence and abundance in Mesouralic and Siberian ecosystems [49]. All given geographic areas of research are ecosystems with homogenous arboreal composition, characterized by a single dominant species even in non-climax ecosystems and cover large geographic span. Influence of different ecosystems, geographic location and climate is noted for similar species [50] yet remain not entirely researched in huge span of environmental factors for P. oblongopunctatus.

Sampling area included the vast territory in different provinces of Russia and the one site in Belarus (Fig. 1). Studied localities differed in three degrees in latitude and twenty nine degrees in longtitue. In relation to latitude we considered it was sufficiently enough according to the several papers devoted to latitude gradient investigations in different invertebrate taxa life-traits [51-53]. Each locality is situated in reserve areas and the plots studied have similar vegetation. They were not chosen by chance. Systematic annual observation in flora and fauna (including ground beetles) have been conducted there, so our samples consisted several years samples in each plot. It is important that there is no anthropogenic impact at those territories. The latter could smear a character of traits variation when latitude was taken as predictor [54].

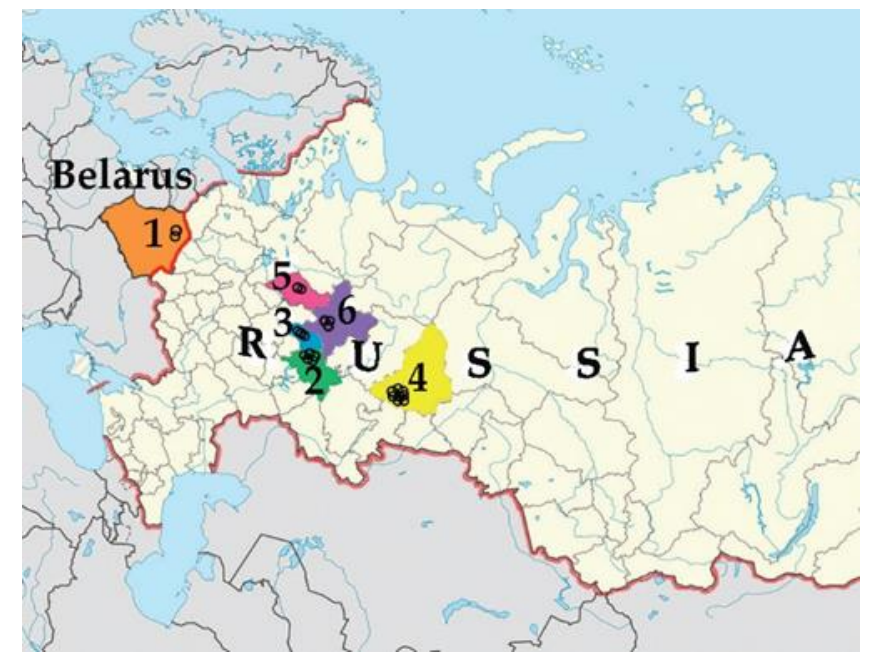

Figure 1Sampling sites of P. oblongopunctatus. 1 - Belarus Republic, 2 -Tatarstan Republic, 3 - Mariy El Republic, 4 Sverdlovsk Province, 5 - Kostroma Province, 6 - Kirov Province.

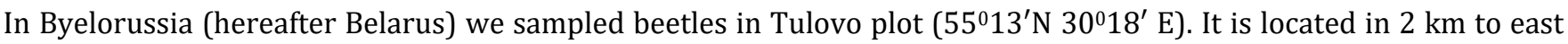
from Vitebsk city at the Tulovskoe Lake shore. It is the forest with pine, oak, alder, willow, not disturbed by recreation.

In Tatarstan Republic (hereafter Tatarstan) beetles were sampled in Volga-Kama State Nature Reserve $\left(55^{\circ} 40^{\prime} \mathrm{N} 48^{\circ} 43^{\prime}\right.$ E). Its area encompasses two partitions with different environmental conditions, which were regarded as different geographic localities. Beetles were sampled in lime and pine forest plots.

In Mariy El Republic (hereafter Mariy El) beetles were sampled at the territory of State Nature Reserve "Bolshaya Kokshaga”, situated in Basin of Bolshaya Kokshaga River (56 $37^{\prime}$ N $47^{0} 57^{\prime}$ E). The reserve is majorly covered by pine forests and geographically situated closely to Volga-Kama reserve. 
Sverdlovsk. The locality denotes territory in Sverdlovsk oblast (hereafter Sverdlovsk) - Visimskiy reserve. It is situated in low mountains part of Middle Urals in the moderate continental boreal climate zone $\left(57^{0} 18^{\prime} \mathrm{N} 59^{0} 55^{\prime} \mathrm{E}\right)$. Beetles were sampled at the different aged forest plots characterized by recovering from several wildfires dating 1920, 1998, 2010 in fir dominated areas.

Kostroma oblast' (hereafter Kostroma) (Kalinki village) (57048' N 41019' E) represents fir dominated ecosystem recovery after felling of the native fir forest in recent decades.

Kirov oblast (hereafter Kirov). Beetles were sampled in “Nurgush" State Nature Reserve (58000' N 48027' E). It includes floodplain plots of Vyatka river. According to geographical zoning it relates to the South taiga and broad leaved forests zone. Beetles were sampled in spruce, lime and oak forests.

\section{Study design.}

Beetles were sampled in the given regions in 2010 - 2018. All beetles captured in each locality during that period formed the dataset for morphometric analysis for that locality. Studied animals were captured using pitfall traps with saline solution. Each sampling plot comprised a direct line of traps with over $10 \mathrm{~m}$ distance betwixt each. Sampling trap exposition lasted approximately 5 days length [55]. Subsequently, animals were preserved in $70 \%$ alcohol prior to taxonomic differentiation and were put straightened on cotton paddings thereafter.

All paddings with captured beetles were transferred to Laboratory of Biomonitoring (The Institute of Problems in Ecology and Mineral Wealth, Tatarstan Academy of Sciences) for photographing. All photos were taken by one person using the same method. Morphometric data was collected from images taken by Nikon D5100 camera with custom opaque light disperser and a box with opaque reflective surface. Measurements were made using program, designated specifically for the given method of measurement and utilized distance between manually pointed out elements of photos' arrays as terminal point of measurements and fiducial scale, using the last to bind real scale to array output data.

Utilized morphometric data corresponded to six linear scalar float recordings as dependent variables and is given for following values (denoting letters are given as Cyrillic transliteration of reference material's source) by R.A. Sukhodolskaya [56] (Fig. 2)

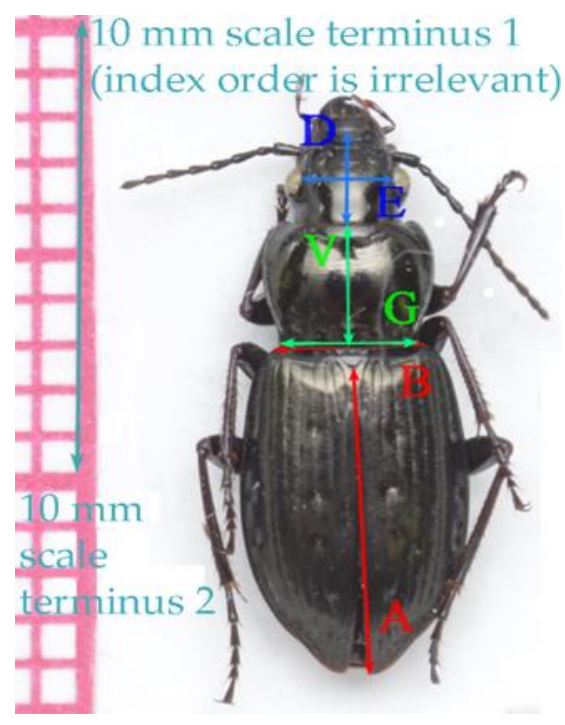

Figure 2 Placement of morphometric measurements.

A - Elytra length as distance between posterior end of scutellum and terminus of right elytron (in absence case of intact right elytron, left one is acceptable).

B - Elytra width as distance between anterior-distal corners of elytra.

V - Pronotum length measured along of central furrow pronotum.

$\mathrm{G}$ - Pronotum width as distance between posterior corners of pronotum. 
D - Head length as distance between labrum and juncture of occiput and postgena.

$\mathrm{E}$ - Head width as distance between proximal innermost sides of eyes.

Measured sample size is presented in Table 1.

Table 1Sample size of measured P. oblongopunctatus

\begin{tabular}{|l|l|l|l|}
\hline & Numberof studied plots & Females & Males \\
\hline Byelorussia & 2 & 12 & 37 \\
\hline Tatarstan & 5 & 512 & 709 \\
\hline Mariy El & 3 & 81 & 72 \\
\hline Sverdlovsk & 8 & 709 & 672 \\
\hline Kostroma & 2 & 174 & 170 \\
\hline Kirov & 3 & 92 & 54 \\
\hline
\end{tabular}

Data processing. In R environment we used regression-based ANOVA to detect effect $a_{S_{-} N}$ of difference in latitude (S_N), effect of Sex $a_{S e x}$, and effect of their interaction $a_{S e x, S_{-} N}$ on beetles traits variation. The models were as follows:

Trait $=\mathrm{a}_{0}+\mathrm{aSex}_{\mathrm{S}}+\mathrm{as}_{-} \mathrm{N}+\mathrm{a} \mathrm{Sex}_{\mathrm{S}-\mathrm{N}}+\varepsilon$

If the interaction was significant, both variables were considered significant also. If the interaction was not significant, we conduct the type-II ANOVA to detect the significance of the main effects:

Trait $=\mathrm{a}_{0}+\mathrm{a} \mathrm{Sex}_{\mathrm{a}}+\mathrm{as} \mathrm{N}+\varepsilon$

The second aim of our work was the comparative analysis of steepness in traits variation from south to north in males and females. The general method of such analysis was presented in review article by [27]. They used regression analysis to evaluate the steepness of body size values shifts in males and females in latitude gradient. The work was done, by the way, on the large data set, taken from the vast spectrum of papers, and the information about body size was based on various traits variation got by various methods. In this regard we strictly adhered to the method of uniformity of measurements: they were done by the single staff on the material, sampled ourselves. The gradient assumes uniformity of changes and numerical value of the latitude. Instead we used qualitative (but not quantitative) variables. We used the couples of neighboring in latitude regions (eg. Belarus_Tatarstan, Tatarstan_Mariy El etc.). Accordingly traits shifts and their significance were estimated for the couple of regions. In addition we could not apply the simple regression analysis in our case for two reasons: (i) body size variation in the species studied could be saw-tooth, as it had been shown to another ground beetle - Pterostichus melanarius III [57]. Then regression coefficient would be zero though the amplitude of trait values would be high. In point of fact we had to estimate the amplitude of traits variation in males and females and apply the comparative analysis; (ii) we had very few strict values of latitude.

That is why we conducted the following models for estimation of steepness in females and males trait variation. We numbered all regions studied from 1 to 6 (from the southmost latitude to the northmost), and used numbers as scalars variables in linear model, but in each model we used data on only two neighboring regions. Namely, the first region was compared with the second, the second with the third etc. As in each case we had the only two regions, the simple regression model calculated coefficient, equal to difference between the neighboring regions and estimates its significance.

We used "Sex" as categorical variable, base level - females. The model estimates:

- Intercept - trait mean in females at the region with lower latitude;

- $\quad$ fSexMale - how males differ from females at lower latitude;

- $\quad$ curS_NID - the change in trait when going one step to the higher latitude for females;

- fSexMale:curS_NID -the change in trait when going one step to the higher latitude for males, compared to females. 


\section{Results}

ANOVA showed that sampling region latitude and sex and their interaction in most cases affected significantly beetles body size. Tables 2, 3 demonstrate elytra length variation.

Table 2 ANOVA results of latitude and sex interaction effect on elytra length variation in P. oblongopunctatus (A= $\mathrm{a}_{0}+\mathrm{a}_{\mathrm{Sex}}+\mathrm{a}_{\mathrm{S}} \mathrm{N}+\mathrm{a}$ Sex,S-N$+\varepsilon$ ).

\begin{tabular}{|l|l|l|c|}
\hline & Df & F value & p-value \\
\hline asex,,$-\mathrm{N}$ & 5 & 3.22 & $\mathbf{0 . 0 0 4}$ \\
\hline
\end{tabular}

Hereinafter: $\mathrm{a}_{0}$ is constant, $\mathrm{a}_{\text {sex }}$ - sex effect, as_N - latitude effect, and asex,S-N - interaction between the sex and latitude effect, and $\varepsilon$ - random error. Since the interaction is significant, asex and as_N are considered as significant also.

Table 3 ANOVA results of latitude and sex effects on elytra length variation in P. oblongopunctatus $(\mathrm{A}=$ $\mathrm{a}_{0}+\mathrm{aSex}_{\mathrm{S}}+\mathrm{as}_{-} \mathrm{N}+\varepsilon$

\begin{tabular}{|l|l|l|l|}
\hline & Df & F value & p-value \\
\hline asex & 1 & 273.46 & $<2.2 \mathrm{e}-16$ \\
\hline as_N & 5 & 141.38 & $<2.2 \mathrm{e}-16$ \\
\hline
\end{tabular}

In elytra width variation no interaction was detected between latitude and sex in their effect, but separately they affected significantly. The same was observed in relation of pronotum length and width and the distance between eyes, but on the head length latitude and sex interaction affected.
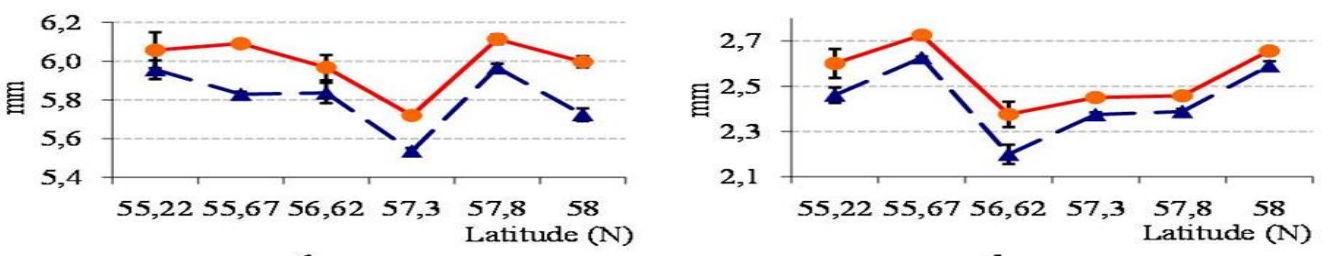

1
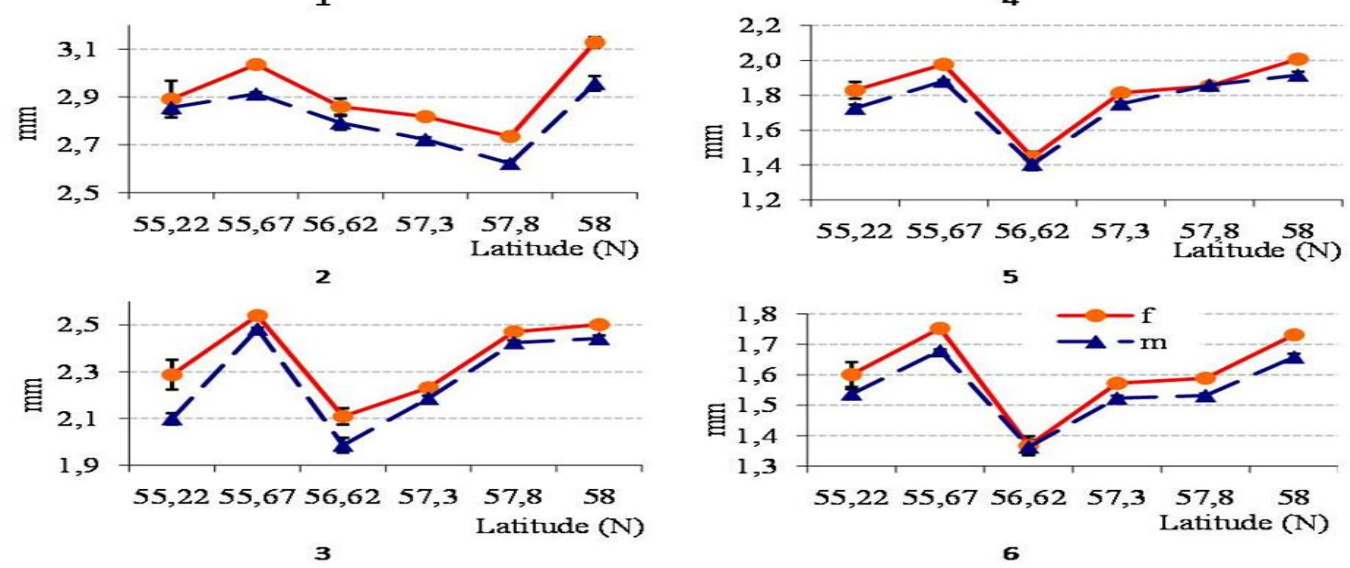

Figure 3 Traits variation in P. oblongopunctatus. 1 - elytra length, 2 - elytra width, 3 - pronotum length, 4 - pronotum width, 5 - head length, 6 - distance between eyes.

Different parts of the body in species studied varied differently in latitude gradient. Elytra length decreased, then increased and again decreased (Figure 3). Taking into account that listed sites were organized according their latitude coordinates (from south to north) we argue, that such the shifts were registered exactly in latitude gradient. Moreover, according to ANOVA and standard errors they were statistically reliable. Elytra width decreasing occurred towards the 
higher latitude region and then increased also. Pronotum size sharply increased from the most southern region to the next and was the smallest at the middle latitude. The similar tendencies came to light in relation to head size variation.

Common to all cases was that means of females traits were higher than males ones. The exception were the only five cases - elytra length in Belarus, elytra width - in Belarus and Mariy El and two head traits in Mariy El. Thus, sexual size dimorphism in P. oblongopunctatus was female-biase.

The next step in our investigations was estimating the steepness of traits variation in males and females. We performed the series of models. In each case we compared data at southern latitude with the neighboring one to the located north. Below in text we present several tables, concerning traits variation in males and females, when comparing data from two neighboring latitudes (from south to north) (Tables 4 - 6). The explanation to tables are given right below them.

Table 4 Linear model results for elytra width changes, when comparing data from Belarus (the most southern latitude, 55,220 ) and Tatarstan (the next region towards the North, 55,670)

\begin{tabular}{|l|l|l|l|l|}
\hline & Estimate & Std. Error & t value & p-value \\
\hline (Intercept) & 2.75 & 0.11 & 25.69 & $<\mathbf{2 e - 1 6}$ \\
\hline fSexMale & 0.05 & 0.12 & 0.43 & 0.666 \\
\hline curS_NID & 0.15 & 0.05 & 2.71 & $\mathbf{0 . 0 0 7}$ \\
\hline fSexMale: curS_NID & -0.08 & 0.06 & -1.42 & 0.153 \\
\hline
\end{tabular}

Intercept - is the elytra width value in females in Belarus; fSexMale - the difference of elytra mean in males if compared to females, we see that in Belarus males did not differ significantly from females; when transiting to the more northern latitude (Tatarstan) the mean elytra width in females (curS_NID=0.15), that shift was significant; the mean elytra width in males changed with the "minus" sign in relation to shift in females, but that shift was not significant; so we conclude that the steepness of shifts in females and males when transiting from Belarus to Tatarstan was equal.

Table 5 Linear model results for pronotum length changes, when comparing data from Belarus (the most southern latitude, 55,220) and Tatarstan (the next region towards the North, 55,670)

\begin{tabular}{|l|l|l|l|l|}
\hline & Estimate & Std. Error & t value & p-value \\
\hline (Intercept) & 2.03 & 0.07 & 28.58 & $<2 e-16$ \\
\hline fSexMale & -0.31 & 0.08 & -3.89 & $<\mathbf{0 . 0 0 1}$ \\
\hline curS_NID & 0.25 & 0.04 & 7.11 & $\mathbf{1 . 9 7 e - 1 2}$ \\
\hline fSexMale: curS_NID & 0.25 & 0.04 & 3.14 & $\mathbf{0 . 0 0 2}$ \\
\hline
\end{tabular}

Again, Intercept is the trait value (pronotum length mean, in this case) in females in Belarus; traits value in Belarus males (fSexMale=-0.31) was smaller, and that difference was significant, it indicates that by this trait Belarus females were larger than males; when transiting northwards (to Tatarstan) females pronotum length increased (curS_NID=0.25) and that increment was significant; males trait increment if compared with females one was significant too and had positive sign (fSexMale: curS_NID=0.25). So the increase of trait value was steeper in males, than in females. 
Table 6 Linear model results for elytra length changes, when comparing data from Tatarstan (the most southern latitude, 55,670) and Mariy El (the next region towards the North, 56, 620

\begin{tabular}{|l|l|l|l|l|}
\hline & Estimate & Std. Error & t value & p-value \\
\hline (Intercept) & 6.22 & 0.06 & 128.79 & $<\mathbf{2 e - 1 6}$ \\
\hline fSexMale & -0.40 & 0.07 & -5.85 & $\mathbf{6 . 2 6 e - 0 9}$ \\
\hline curS_NID & -0.12 & 0.04 & -3.19 & $\mathbf{0 . 0 0 1}$ \\
\hline fSexMale: curS_NID & 0.13 & 0.05 & 2.29 & $\mathbf{0 . 0 2 2}$ \\
\hline
\end{tabular}

The last variant of models results, when the steepness of shifts was higher in females. Intercept is the trait value (elytra length mean, in this case) in females in Tatarstan; traits value in Tatarstan males (fSexMale $=-0.40$ ) was smaller, and that difference was significant, it indicated that by this trait Tatarstan females are larger than males; when transiting northwards (to Mariy El) females elytra length decreased (curS_NID=-0.12) and that decrease was significant; males trait shift, on contrary, had positive sign if compared with females (fSexMale: curS_NID=0.13) and was significant. So in this case steepness of shifts was higher in females.

In such the way the shifts in all studied traits and in each pair of adjacent regions (latitudes) were analyzed. So we had 30 pairs of comparisons. All results were summarized (Table 7): we recorded 4 cases out of 30, when the steepness of trait shifts was higher in males, 3 - when it was higher in females and in 23 cases it was equal in both sexes. So we conclude that steepness of body size variation in latitude gradient in P. oblongopunctatus is the same in males and females. Illustration of shifts (one case) is presented in Figure 4, the other ones - in the Supplement (Figures S1 - S5). The latter are given to illustrate graphically the absence of differences in traits value shifts in latitude gradient.

Table 7 Steepness of trait shifts in latitude gradient in P. oblongopunctatus. "+" - steepness was higher in males, "-“steepness was higher in females, $\mathrm{n}$ - steepness was equal in both sexes.

\begin{tabular}{|l|l|l|l|l|l|l|}
\hline Regions/Traits & A & B & V & G & D & E \\
\hline Belarus/Tatarstan & $\mathrm{n}$ & $\mathrm{n}$ & + & $\mathrm{n}$ & $\mathrm{n}$ & $\mathrm{n}$ \\
\hline Tatarstan/Mariy El & - & $\mathrm{n}$ & + & + & $\mathrm{n}$ & $\mathrm{n}$ \\
\hline Mariy El/Sverdlovsk & $\mathrm{n}$ & $\mathrm{n}$ & $\mathrm{n}$ & $\mathrm{n}$ & $\mathrm{n}$ & $\mathrm{n}$ \\
\hline Sverdlovsk/Kostroma & $\mathrm{n}$ & $\mathrm{n}$ & $\mathrm{n}$ & $\mathrm{n}$ & + & $\mathrm{n}$ \\
\hline Kostroma/Kirov & + & - & $\mathrm{n}$ & $\mathrm{n}$ & - & $\mathrm{n}$ \\
\hline
\end{tabular}
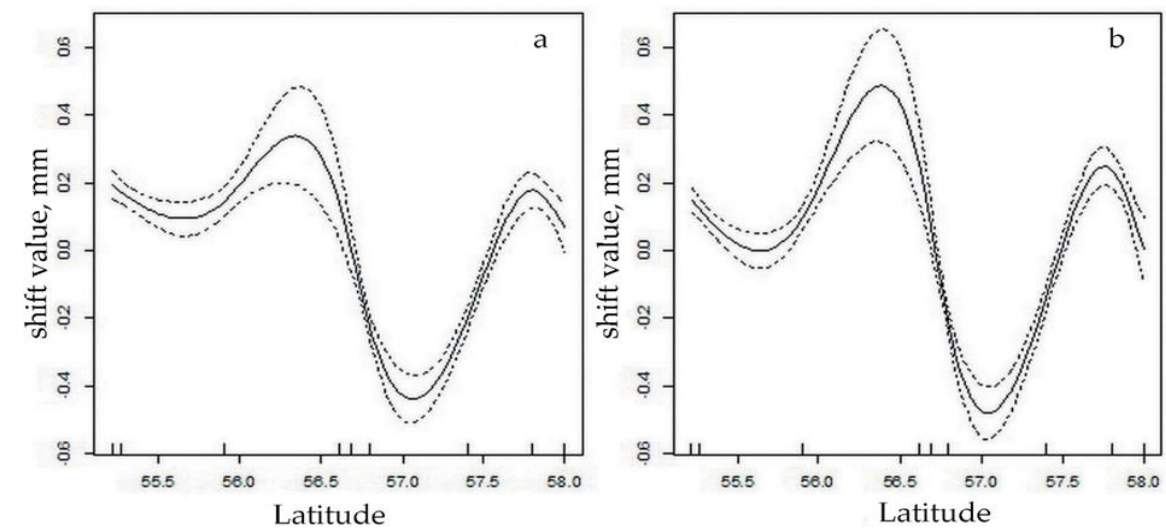

Figure 4 Splines of shifts in elytra length value in latitude gradient in P. oblongopunctatus. a - females, b-males 


\section{Discussion}

Rensch's rule is manifested statistically in allometric slopes greater than one when male size is regressed on female size [18]. In the summarizing review on this item [27] the authors compiled the data in 98 species (vertebrates and invertebrates) and proceeded analysis on females and males body size variation in latitude gradient. In about two-thirds of all species male body size varied more with latitude than female body size, as males showed steeper body sizelatitude relationships than females. But in this content we can add, that the research cited had been done using RVA regressions and the slope value in certain species. We should remember that the curve, reflecting body size variation in latitude gradient, sometimes is a "saw-tooth" one, when the trait mean alternatively increases and then decreases significantly. Saw-tooth clines were cited in claims that Bergmann's rule is invalid, although this was in part due to his strict interpretation of Bergmann's rule as including a temperature-dependent mechanism. These clines can still have an overall upward or downward trend, or the increases and decreases may cancel each other out and lead to a no-trend conclusion.

In our study we had exactly this case. And we undertook fundamentally different approach: we compared the steepness in shifts in males and females sizes in each case of the adjacent latitudes. Sometimes male's shifts were steeper and sometimes - females' ones. But in the overwhelming majority of cases the steepness of shifts was the same in both sexes. It is noteworthy, that our study included six morphometric characters and not always their variations were identical in latitude gradient. For example, elytra length drastically decreased toward Sverdlovsk and in Kostroma significantly increased, but elytra width became lowest exactly in Kostroma. Pronotum and head parameters were the lowest in Mariy El. In our earlier paper we also recorded the uncoordinated intra-species variation of different traits. Elytra length in Ground Beetle CarabusaeruginosusF.-W.did not change in suburban biotopes but elytra width changed significantly, and those shifts were sex-biased [57]. In another carabid - PterostichusmelanariusIll. - the head length of the beetles reacted on habitat vegetation but the head width - did not [58]. Aparently those facts should be taken into account, when exploring body size variation in latitude gradient. So, the type of organ examined for size variation is important: several studies showed Bergmann clines for some morphological characters and converse-Bergmann clines for others within the same populations [59, 60]. Allometric growth complicates body size responds to geographic location [61]. The abundance of no-cline results may thus be due to studies of body parts that do not vary with latitude or altitude even while other parts do. This theory is supported by the higher prevalence of no-cline results among body-part studies relative to whole-body studies. In our case if we had used the simple regression we would get the curve with zero coefficient. Additionally if we analyzed males and females in total we would get no shifts in body size mean at all, while they are actually exists between the regions studied.

Additionally clines in organ size also do not always share the same cellular basis. For example, positive Bergmann clines in wing area in Drosophila subobscura Collin (Diptera: Drosophilidae) in North America are caused by variation in cell area, while those in South American populations and the ancestral European populations are caused by variation in cell number [62]. Ultimately, even if a cline in body size is linked to temperature or another mechanism, whether the variation is due to adaptation of a plastic phenotype during an individual organism's lifetime or is a product of clustering of genes over geographic clines requires specific tests to determine $[63,64]$. Clines also vary over time, which is especially relevant for quickly evolving organisms such as insects. In addition carabids body size depends on various local factors (nutrient source, wintering conditions, soil humidity, vegetation etc.). That is why the data set of our research included samples from several seasons in certain latitude, different types of biotopes and anthropogenic impact in each province. Then we argue that the types of beetles body parts variation are the result of latitude impact. Another problem for researchers who gather insect body size data not from specimens but from previous literature, where body size was an ancillary data point in unrelated experiments (see [27, 28]). In our study all measurements were performed by a single stuff according the single method. And we did not find that male's variation in body size was steeper that female's. So Rensch's rule is not conformed in ground beetle P. oblongopunctatus. Perhaps our results merely reflect greater sampling error in studies with small latitudinal range. Nevertheless, identifying the putative microevolutionary mechanisms causing Rensch's rule among species requires studying variation in dimorphism among populations in detail in a greater number of species. In our case we do not insist namely on latitude clines. Localities studies differed in climatic factors, longtitude and other factors affecting body size in insects. The aim of the study was to trace the steepness of traits variation between localities studied. And that steepness was equal in males and females.

\section{Conclusion}

We found that sexual-size dimorphism in ground beetle P. oblongopunctatus is female-biased in relation to all six metric traits studied. Body size variation in females and males in latitude gradient resembles saw-tooth one and the steepness of it is equal in both sexes. The importance of comprehensive research in the study of morphometric variation in a wide 
variety of taxa should be emphasized. On the one hand several traits should be taken into analysis because different traits variation can have different directions even among conspecificians. From the other hand, even such the in-depth intraspecific study can not to be considered complete because plenty local factors affect body size variation in insects. Then broad-scale compilation investigations are welcome for understanding general patterns.

\section{Compliance with ethical standards}

\section{Acknowledgments}

We thank all staff of corresponding Laboratories, who sampled beetles in different provinces of Russia and Belarus

\section{Disclosure of conflict of interest}

The authors declare no conflict of interest.

\section{Statement of informed consent}

Informed consent was obtained from all participants included in the study.

\section{References}

[1] Cushman JH, Lawton JH, Manly BF. Latitudinal patterns in European ant assemblages: variation in species richness and body size. Oecologia. 1993; 95:30-37.

[2] Barlow ND. Size distributions of butterfly species and the effect of latitude on species sizes. Oikos. 1994; 326332.

[3] Hawkins BA, Lawton JH. Latitudinal gradients in butterfly body sizes: is there a general pattern? Oecologia. 1995; 102:31-36.

[4] Blackburn TM, Gaston KJ, Loder N. Geographic gradients in body size: a clarification of Bergmann's rule. Diversity and distributions. 1999; 5:165-174.

[5] Ray C.The application of Bergmann's and Allen's rules to the poikilotherms. Journal of morphology. 1960; 106:85108.

[6] Stevenson R. Body size and limits to the daily range of body temperature in terrestrial ectotherms. The American Naturalist. 1985; 125:102-117.

[7] Conover DO, Present TM. Countergradient variation in growth rate: compensation for length of the growing season among Atlantic silversides from different latitudes. Oecologia. 1990; 83:316-324.

[8] Masaki S. Geographic variation and climatic adaptation in a field cricket (Orthoptera: Gryllidae). Evolution. 1967; 725-741.

[9] Masaki S. Climatic adaptation and photoperiodic response in the band-legged ground cricket. Evolution. 1972; 587-600.

[10] Roff D. Optimizing development time in a seasonal environment: the 'ups and downs' of clinal variation. Oecologia. 1980; 45:202-208.

[11] ROFF D. Phemological adaptation in a seasonal environment: a theoretical perspective. Diapose and Life Cycle Strategies in Insects. 1983; 253-270.

[12] Iwasa Y, Ezoe H, Yamauchi A. Evolutionarily stable seasonal timing of univoltine and bivoltine insects. In Insect life-cycle polymorphism. Springer. 1994; 69-89.

[13] Nygren GH, Bergström A, Nylin S. Latitudinal body size clines in the butterfly Polyommatus icarus are shaped by gene-environment interactions. Journal of Insect Science. 2008; 8:47.

[14] Välimäki P, Kivelä S, Mäenpää M, Tammaru T. Latitudinal clines in alternative life histories in a geometrid moth. Journal of Evolutionary Biology. 2013; 26:118-129.

[15] Conover DO, Schultz ET. Phenotypic similarity and the evolutionary significance of countergradient variation. Trends in Ecology \& Evolution. 1995; 10:248-252. 
[16] Rensch B. Die Abhängigkeit der relativen Sexualdifferenz von der Körpergrösse. Bonner Zoologische Beiträge. $1950 ; 1: 58-69$.

[17] Abouheif E, Fairbairn DJ. A comparative analysis of allometry for sexual size dimorphism: assessing Rensch's rule. The American Naturalist. 1997; 149:540-562.

[18] Fairbairn DJ. Allometry for sexual size dimorphism: pattern and process in the coevolution of body size in males and females. Annual review of ecology and systematics. 1997; 28:659-687.

[19] Fairbairn DJ, Blanckenhorn WU, Székely T. Sex, size and gender roles: evolutionary studies of sexual size dimorphism. Oxford University Press. 2007.

[20] Fairbairn D. Introduction: the enigma of sexual size dimorphism. Sex, size and gender roles Evolutionary studies of sexual dimorphism. 2007:1-15.

[21] Bidau CJ, Taffarel A, Castillo ER. Breaking the rule: multiple patterns of scaling of sexual size dimorphism with body size in orthopteroid insects. Revista de la Sociedad Entomológica Argentina. 2016; 75.

[22] Fairbairn DJ, Preziosi RF. Sexual selection and the evolution of allometry for sexual size dimorphism in the water strider, Aquarius remigis. The American Naturalist. 1994; 144:101-118.

[23] Kraushaar U, Blanckenhorn WU. Population variation in sexual selection and its effect on size allometry in two dung fly species with contrasting sexual size dimorphism. Evolution. 2002; 56:307-321.

[24] Gustafsson A, Lindenfors P. Human size evolution: no evolutionary allometric relationship between male and female stature. Journal of human evolution. 2004; 47:253-266.

[25] Fairbairn DJ. Allometry for sexual size dimorphism: testing two hypotheses for Rensch's rule in the water strider Aquarius remigis. The American Naturalist. 2005; 166:S69-S84.

[26] Young KA. Life-history variation and allometry for sexual size dimorphism in Pacific salmon and trout. Proceedings of the Royal Society B: Biological Sciences. 2005; 272:167-172.

[27] Blanckenhorn WU, Stillwell RC, Young KA, Fox CW, Ashton KG. When Rensch meets Bergmann: does sexual size dimorphism change systematically with latitude? Evolution. 2006; 60:2004-2011.

[28] Blanckenhorn W, Demont M. Bergmann and converse Bergmann latitudinal clines in arthropods: two ends of a continuum? Integrative and Comparative Biology. 2004; 44:413-424.

[29] Ashton K. Are there general intraspecific patterns of body size variation in relation to latitude (and temperature) for tetrapod vertebrates. Integr Comp Biol. 2004; 44:401-412.

[30] Koivula MJ. Useful model organisms, indicators, or both? Ground beetles (Coleoptera, Carabidae) reflecting environmental conditions. ZooKeys. 2011;287.

[31] Homburg K, Schuldt A, Drees C, Assmann T. Broad-scale geographic patterns in body size and hind wing development of western Palaearctic carabid beetles (Coleoptera: Carabidae). Ecography .2013; 36:166-177.

[32] Sota T, Takami Y, Kubota K, Ujiie M, Ishikawa R. Interspecific body size differentiation in species assemblages of the carabid subgenus Ohomopterus in Japan. Population Ecology. 2000; 42:279-291.

[33] Mrazović A, Rukavina I, Jelaska LŠ, Kučinić M. Body and wing size changes in Carabid beetles (Coleoptera: Carabidae) along the elevation gradient in forest habitats of Učka mountain. In 22 Symposium internationale entomofaunisticum Europae centralis-SIEEC22. 2011.

[34] Tsuchiya Y, Takami Y, Okuzaki Y, Sota T. Genetic differences and phenotypic plasticity in body size between highand low-altitude populations of the ground beetle C arabus tosanus. Journal of Evolutionary Biology. 2012; 25:1835-1842.

[35] Cvetkovska-Gjorgjievska A, Hristovski S, Prelić D, Jelaska LŠ, Slavevska-Stamenković V, Ristovska M. Body size and mean individual biomass variation of ground-beetles community (Coleoptera: Carabidae) as a response to increasing altitude and associated vegetation types in mountainous ecosystem. Biologia. 2017; 72:1059-1066.

[36] Kryzhanovsky 0: Fam. Carabidae-ground beetles. Key to Insects of the European USSR. 1965; 2:29-77.

[37] Sukhodolskaya RA, Avtaeva TA, Saveliev AA, Vavilov DN. Sexual Size Dimorphism in Ground Beetle Carabus cumanus Fischer von Waldheim, 1823 (Coleoptera, Carabidae) and its Variation in Different Traits. Baltic Journal of Coleopterology. 2019; 19:89-100. 
[38] Sukhodolskaya RA, Saveliev AA. Impact of environmental factors on the body shape variation and sexual shape dimorphism in Carabus granulatus L. (Coleoptera: Carabidae). Zoological Systematics. 2017; 42:71-89.

[39] Sukhodolskaya RA, Saveliev AA, Muhammetnabiev TR. Sexual Dimorphism of Insects and Conditions of Its Manifestation. Research Journal of Pharmaceutical, Biological and Chemical Sciences. 2016; 7:1992-2001.

[40] Sukhodolskaya RA. Intraspecific body size variation in ground beetles (Coleoptera, Carabidae) in urbansuburban-rural-natural gradient. Acta Biologica Universitatis Daugavpiliensis. 2013; 13:121-128.

[41] Shelomi M. Where are we now? Bergmann's rule sensu lato in insects. The American Naturalist. 2012; 180:511519.

[42] Brygadyrenko V. Evaluation of ecological niches of abundant species of Poecilus and Pterostichus (Coleoptera: Carabidae) in forests of steppe zone of Ukraine. Entomologica Fennica. 2016; 27:81-100.

[43] Irmler U. Long-term fluctuations of ground beetles in a wood-agrarian landscape of northern Germany (Coleoptera: Carabidae). Entomologia generalis. 2007:13-32.

[44] Magura T, Tóthmérész B, Elek Z. Distribution of carabids following leaf-litter manipulation in a Norway spruce plantation. In How to protect or what we know about Carabid Beetles X European Carabidologist Meeting, Tuczno. 2001; 247-258.

[45] Avtaeva T, Sukhodolskaya R, Skripchinsky A, Brygadyrenko V. Range of Pterostichus oblongopunctatus(Coleoptera, Carabidae) in conditions of global climate change. Biosystems Diversity. $2019 ; 27$.

[46] Lagisz M. Changes in morphology of the ground beetle Pterostichus oblongopunctatusF.(Coleoptera; Carabidae) from vicinities of a zinc and lead smelter. Environmental Toxicology and Chemistry: An International Journal. 2008; 27:1744-1747.

[47] Belskaya E, Zolotarev M, Zinovyev E: Carabidae assemblages in pine forests with different recreation regimes within and outside a megalopolis. Urban Ecosystems. 2020; 23:27-38.

[48] Kryzhanovsky O. Fam. Carabidae-ground beetles. Key to Insects of the European USSR. 1965; 2:29-77.

[49] Sukhodolskaya Raisa A, Saveliev Anatoliy A, Gordienko Tatyana A, Vavilov Dmitriy N. Sexual size dimorphism in Ground Beetles and its modeling in latitude gradient. GSC Biological and Pharmaceutical Sciences. 2018; 3:11-18.

[50] Sukhodolskaya R, Ananina T. Elevation changes of morphometric traits structure in Pterostichus montanus Motch.(Coleoptera, Carabidae). Asian Journal of Biology. 2017;1-9.

[51] Cooper M. Latitudinal gradient in southern African forest millipede species richness. Journal of Natural History 2020.

[52] Vandewoestijne S, Van Dyck H. Flight morphology along a latitudinal gradient in a butterfly: do geographic clines differ between agricultural and woodland landscapes? Ecography. 2011; 34:876-886.

[53] Śniegula S, Gołąb MJ. Test for latitudinal variation of life history, behavior and mortality in the strictly univoltine damselfly S ympecma fusca (Z ygoptera: L estidae). Entomological Science. 2015; 18:479-488

[54] Beasley DE, Penick CA, Boateng NS, Menninger HL, Dunn RR. Urbanization disrupts latitude-size rule in 17-year cicadas. Ecology and evolution. 2018; 8:2534-2541

[55] Barber H. Traps for cave-inhabiting insects. Journal of the Elisha Mitchell Scientific Society. 1931; 46:259-266.

[56] Sukhodolskaya R, Saveliev A. Body size variation in Ground Beetles (Coleoptera: Carabidae) in latitude gradient. Journal of Periodicum Biologorum. 2016; 3:273-278

[57] Sukhodolskaya R, Eremeeva N. Body size and shape variation in Ground Beetle Carabus aeruginosus F.-W., 1822 (Coleoptera, Carabidae). Contemporary Problems of Ecology. 2013; 6:609-615.

[58] Sukhodolskaya R. Variation in body size and body shape in ground beetle Pterostichus melanarius Ill.(Coleoptera, Carabidae). Journal of Agri-Food and Applied Sciences. 2014; 2:196-205.

[59] Krasnov B, Ward D, Shenbrot G. Body size and leg length variation in several species of darkling beetles (Coleoptera: Tenebrionidae) along a rainfall and altitudinal gradient in the Negev Desert (Israel). Journal of Arid Environments. 1996; 34:477-489.

[60] Jang Y, Won Y-J, Choe JC. Convergent and divergent patterns of morphological differentiation provide more evidence for reproductive character displacement in a wood cricket Gryllus fultoni (Orthoptera: Gryllidae). BMC evolutionary biology. 2009; 9:27. 
[61] De Los Santos A, Gómez-González L, Alonso C, Arbelo C, De Nicolás J. Adaptive trends of darkling beetles (Col. Tenebrionidae) on environmental gradients on the island of Tenerife (Canary Islands). Journal of Arid Environments. 2000; 45:85-98.

[62] Calboli FC, Gilchrist GW, Partridge L. Different cell size and cell number contribution in two newly established and one ancient body size cline of Drosophila subobscura. Evolution. 2003; 57:566-573.

[63] Partridge L, Coyne JA. Bergmann's rule in ectotherms: is it adaptive? Evolution. 1997; 51:632-635.

[64] Karl I. Thermal adaptation in butterflies: patterns, significance and mechanisms. 2008. 